\title{
ATTACHMENT VERSUS CLASP RETAINED REMOVABLE PARTIAL DENTURES -A RANDOMIZED CONTROLLED CLINICAL TRIAL
}

\author{
Dina Mohamed Ahmed Elawady* and Wafaa Ibrahim Ibrahim**
}

\begin{abstract}
Purpose: to compare two retainer designs for free end removable partial dentures (RPDs) by measuring the patient satisfaction, abutment tooth survival, bone height loss and pocket depth.

Materials and Methods: Group 1: Fourteen patients receiving attachment-retained RPDs while group 2: Fourteen patients receiving clasp-retained RPDs. The assessment included patient satisfaction, survival of the terminal abutments, bone height loss and pocket depth. All patients were evaluated clinically and radiographically at the time of RPD insertion, twelve months and 24 months thereafter. Mann Whitney U test for independent samples was used for comparison of $\%$ change of patient satisfaction. Wilcoxon signed rank test for paired (matched) samples was used within group comparison of patient satisfaction before and after treatment. Survival analysis was done using Kaplan Meier statistics. For bone height, independent t-test was used and student's $\mathrm{t}$ - test was used for pocket depth comparison.
\end{abstract}

Results: There was a significant difference before and after treatment scores in Oral Health Impact Profile-14(OHIP-14), Orofacial Esthetic Scale (OES) and Chewing Function Questionnaire $(C F Q)$ questionnaires in the clasp retained RPD group with $P$ value $=(0.001,0.001$ and 0.003$)$ respectively. Regarding the attachment retained RPD group, there was a significant difference before and after treatment scores with $\mathrm{P}$ value $=0.001$ for the three questionnaires. Within group comparison it was found that there was a significant difference in OHIP-14 ( $\mathrm{P}=0.002)$ and OES $(\mathrm{P}<0.001)$ while there was no significant difference in $\mathrm{CFQ}$ between both groups $(\mathrm{P}=0.191)$. There was no statistically significant difference between both groups in terminal abutment survival $(\mathrm{P}=0.149)$ and percent change of the mean probing pocket depth from baseline to 24 months ( $\mathrm{P}=0.05)$. However, regarding the effect of time on bone height change percentage for each group, a significant difference was found between groups at baseline-twenty-four month's interval (P-value $<0.05$ ).

Conclusion: Within the limitations of the present study, all patients have shown improvement in OHRQoL, esthetics and chewing function after treatment with RPDs with better results in the attachment retained RPD. However, regarding the terminal abutment survival, mean probing pocket depth and bone height change, clinically significant better results were revealed in clasp-retained RPD compared to attachment-retained RPDs.

* Lecturer of Prosthodontics, Faculty of Dentistry, Modern Science and Arts University (MSA), Egypt

** Lecturer of Prosthodontics, Faculty of Oral \& Dental Medicine, Delta University for Science \& Technology, Egypt. 


\section{INTRODUCTION}

A significant challenge is encountered in restoring mandibular free end partially edentulous cases where the edentulous ridge is without a terminal abutment tooth. Due to the difference in the compressibility of the supporting tissues it is difficult to design a prosthesis without damaging these tissues. ${ }^{1}$

Partially edentulous patients with loss of posterior dentition can be left with a short dental arch (SDA), restored with fixed implant-supported denture or removable partial denture (RPD). ${ }^{1-2}$ Implantsupported prosthesis can be contraindicated in some patients as a result of deficiency of supporting bone, limited finance, or systemic diseases.

Conflicting results have been shown regarding clasp-retained RPDs. Some studies revealed that they can cause damage to the teeth and the supporting structures, ${ }^{3-4}$ others found satisfactory results with clasp-retained RPDs ${ }^{5}$. Some studies reported 90\% survival rate after ten years and a decreased rate of loss of abutment teeth., ${ }^{4,5}$ The main advantages of clasp retained-RPD include reduced fabrication time and cost, while compromised esthetic has been believed to be a drawback..$^{6-7}$

RPDs retained by attachments provide better esthetics, restore mastication and protect abutment teeth and residual ridges. Extra-coronal attachments when compared to intra-coronal attachments need less tooth reduction and avoid the risk of pulpal exposure. ${ }^{8}$ Also when few or weak abutments are remaining, a great need of free movements of the attachments is necessary to direct destructive forces towards the residual ridge instead of the abutment tooth. ${ }^{8}$

Patient's satisfaction depends on several factors including patient's personality and acceptance to RPD, preceding experience with RPD, and RPD design and method of fabrication., ${ }^{9}, 10$ Acceptance of RPD is affected by retention, chewing function and esthetics. ${ }^{11}$ Dissatisfaction with RPD depends on the possibility of damage of the remaining teeth or oral tissues with caries or plaque accumulation and denture stomatitis. ${ }^{12,13}$ OHIP questionnaire is the most worldwide used questionnaire to measure (OHRQoL). ${ }^{14,15}$ The OES ${ }^{16,17}$ and the CFQ ${ }^{18}$ are newly developed to evaluate esthetics and chewing function respectively.

The influence of RPD on pocket depth and marginal bone loss has been studied by some articles. 19,20 Many studies reported severe periodontal traumas and bone loss, ${ }^{21}$ However, in other studies better outcomes or no changes were described. ${ }^{22}$

The available articles were almost in vitro studies. However, it is hard to imitate the viscoelasticity of periodontal ligament and mucosa of the alveolar ridge, only analyzing it intraorally can show the actual conditions.

Long term success rate of RPDs with careful plan and design are recognized ${ }^{23,24,25}$. However, to the authors' knowledge, there are no randomized clinical trials comparing patient satisfaction, abutment tooth survival, bone height loss and pocket depth in attachment-retained versus claspretained RPDs.

Therefore, the aim of this study was to compare these two types of retainers for free end RPDs by assessing the patient's satisfaction, abutment tooth survival, bone height loss and pocket depth.

\section{MATERIALS AND METHODS}

\section{Selection of the patients}

Twenty-eight partially edentulous patients were selected from the Outpatient Clinic of the Prosthodontic Department; Faculty of Dentistry, MSA University. The patients agreed with a written informed consent and the MSA University ethics committee review board approved the study. The basic inclusion criteria were mandibular class I Kennedy classification partially edentulous patients with first 
and second premolars remaining as the last abutments. (fig1A)

Selection of patients was based on clinical and radiographic examination by means of preoperative panoramic, periapical radiograph and mounted diagnostic casts.

Patient's age ranging from forty-five to sixty with a mean 51 years old, good oral hygiene measures and with adequate interarch space were included. The selected subjects were systemically free from diseases which may compromise bone e.g. uncontrolled diabetes, blood diseases, hypertension, bone diseases and smoking habits. Patients with skeletal jaw discrepancy (angle's class II or III) were excluded. Patients having periodontally affected teeth, bruxers, irradiated patients were also excluded.

\section{Intraoral assessment:}

\section{1) Visual assessment:}

Oral structures such as the edentulous ridge, tongue, cheeks, lips and palate were examined for any signs of inflammation or ulceration and have been treated prior to prosthetic procedures.

\section{2) Manual assessment:}

Further examination of the residual ridge was done using finger pressure, to verify mucoperiosteal firmness, and distinguish flabby tissues, sharp bony ridges, excessive undercuts and ridge discrepancies.

\section{Mounted diagnostic casts:}

Maxillary and mandibular primary alginate (CA 37, Cavex) impressions were made for fabrication of diagnostic casts which were mounted on an articulator using tentative jaw relation record (fig2a,b). This was important to evaluate interarch distance especially at the attachment proposed sites to accommodate the future prosthesis. The mounted diagnostic casts have been used as well to assess the antro-posterior jaw relation and to design the RPDs.
After the results of clinical and radiographic examinations indicated that the patient is a candidate for RPD; Patients were randomly assigned into two equal groups (each of fourteen patients). Computer generated random numbers were placed inside an opaque sealed envelope, the participants were asked to select envelope and the number inside this envelope determined which group he or she belonged. Patients of Group-1 were allocated to attachment retained RPD group, while those of Group-2 were allocated to clasp retained RPD group.

Patient's allocation concealment was performed and conventional steps for RPD construction were followed for both groups.

Group 1: An extracoronal attachment was placed at the distal side of the right and left second premolar, where the first and the second premolar were splinted.

Group 2: The same design was used with a reversed circumferential clasp and a mesial rest on the right and left second premolar.

Partial denture design was simplified as much as possible to avoid stagnation areas and minimize gingival coverage by retentive components or connectors. Treatment plan was done by the authors (D.A. and W.I.). After preparation of teeth, rubber base (Thixoflex M, Medium viscosity C-silicone, Zhermack, Italy) impressions were made. Pouring of the master casts was done using vacuum-mixed type IV dental stone (Fujirock, GC). The metal frameworks were cast by cobalt-chrome alloy.

For both groups a calibrated dental laboratory fabricated all the dentures. (fig 1\&2) Opposing arches were restored with conventional removable prostheses. Adjustment of occlusion was made and ensured to be uniform and harmonious in both centric and lateral movements. All patients were instructed regarding oral hygiene and periodic follow up. 


\section{FOLLOW UP}

\section{Patient satisfaction}

Patient satisfaction includes general satisfaction and satisfaction with chewing capability and esthetics were measured using a questionnaire. The OHRQoL was evaluated using the OHIP-14 questionnaire ${ }^{26}$ The evaluation was done using Likertscale with score which ranges from 0 to 4 . Thus, the maximum score was 56 and the minimum score was 0 . Higher score corresponds to more unsatisfactory results. The Orofacial Esthetic Scale (OES) ${ }^{27}$ which consists of 8 items was used for assessment of orofacial esthetics. Likert scale ranges from 1 to $5(1=$ complete unsatisfaction; $5=$ complete satisfaction): the total scores ranged from 1 to 40 . High scores show increased satisfaction with esthetics. The Chewing Function Questionnaire (CFQ) was utilized to evaluate the chewing function of patients ${ }^{28}$ which consists of 10 items. Patients evaluated their chewing function using a Likert scale which ranges from 0 to 4 . High scores showed unsatisfactory chewing function. The minimum score was 0 and the maximum was 40 . Patients finished the questionnaires during their first visit to the clinic and then 6 months after receiving their new RPDs.

\section{II survival rate}

The terminal abutments survival was evaluated throughout a 24 months follow up period (fig3A-D).

\section{Radiographic evaluation}

Standardized periapical radiography was achieved using digital periapical radiograph with paralleling technique. Radiographs were recorded by the same radiographic machine (Orix X-ray machine) and exposure parameters. Comparison of the radiographs was done regarding the marginal bone height.

\section{The exposure protocol:}

All patients were instructed to remove any metallic objects that may cast radiopaque shadows on the radiograph. They were instructed to wear a lead apron for protection from radiation (fig4C).

The indicator arm and aiming ring were assembled and the image plate was placed in disposable sleeve. (fig4B) then the long cone of $\mathrm{x}$-ray machine (Orix70, $70 \mathrm{KV}, 8 \mathrm{~mA}$, Italy) was fitted to the aiming ring. (fig 4C).

In all radiographs; the exposure time (0.08 second) was fixed for all patients and the image plate was placed in the vista scanner (fig4a) to have a digital image which was analyzed on the monitor of the workstation.

The Digital images were used to analyze and evaluate marginal bone height changes (linear analysis):

The DBSWIN software was used for assessing mesial and distal marginal bone height around the abutments at time of prosthesis insertion, twelve months and 24 months thereafter.

The distance from the apex of the abutment to the alveolar ridge crest was measured, where a line was drawn tangential to the abutment apex and another line parallel to its long axis (Fig.4D). The mean value of both mesial and distal readings was taken, tabulated and statistically analyzed.

\section{IV pocket depth}

For the terminal abutments; measuring the probing pocket depth was performed at six sites for each tooth (mesio-buccal, buccal, disto-buccal, distolingual, lingual and mesio-lingual) by the William's periodontal probe (fig4E) at time of prosthesis insertion, twelve months and 24 months thereafter.

\section{Data handling and Statistical Analysis:}

Data were statistically described in terms of mean \pm standard deviation $( \pm \mathrm{SD})$, median and range when appropriate. Comparison of $\%$ change of QOL scales among the studied groups was made using Mann Whitney U test for independent samples. Wilcoxon signed rank test for paired (matched) samples was used for within group comparison of 
QOL scales between before and after treatment. Survival analysis was done using Kaplan Meier statistics with the corresponding survival graph. For bone height, independent t-test was used and student's t- test was used for pocket depth comparison. $P$ values less than 0.05 was considered statistically significant. All statistical calculations were made using IBM SPSS computer program (Statistical Package for the Social Science; IBM Corp, Armonk, NY, USA) release 22 for Microsoft Windows.

\section{RESULTS}

Thirteen patients in each group completed the study period as two patients have dropped out. One patient died and the other didn't adhere to the follow up schedule.

\section{Patient satisfaction}

Regarding patient satisfaction for all the three questionnaires, mean and standard deviation were calculated for the percentage of change between the

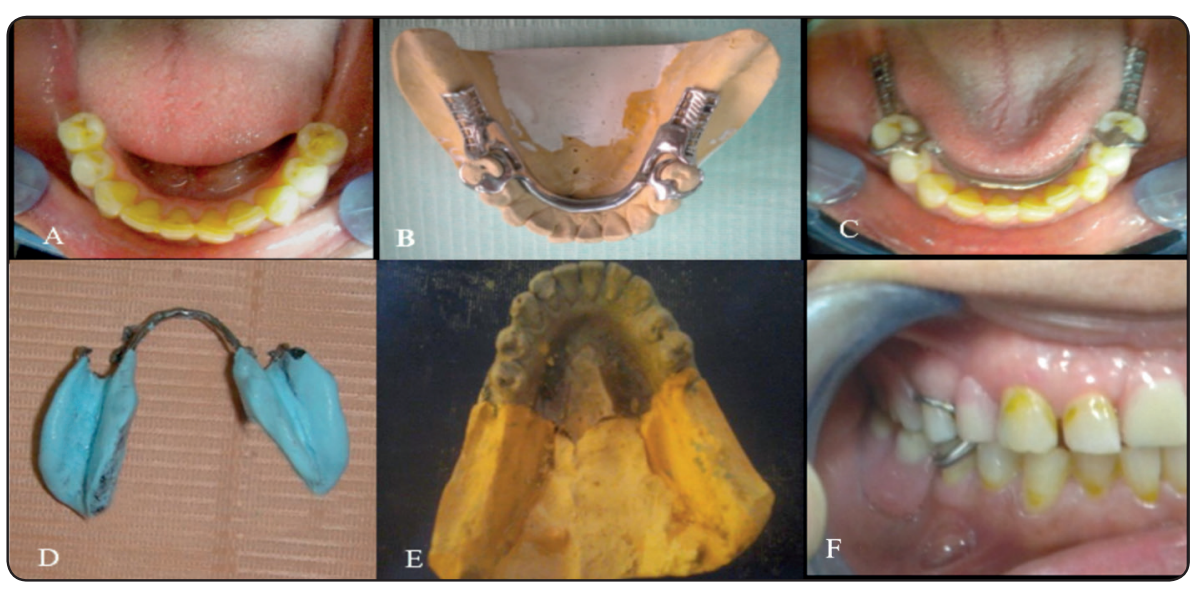

Fig. (1) prosthetic procedure -clasp retained RPD

A) Intra oral photo occlusal view

B) Metal try -in on cast

C) Metal try in patient mouth

D) Altered cast impression

E) Altered cast

F) Denture insertion

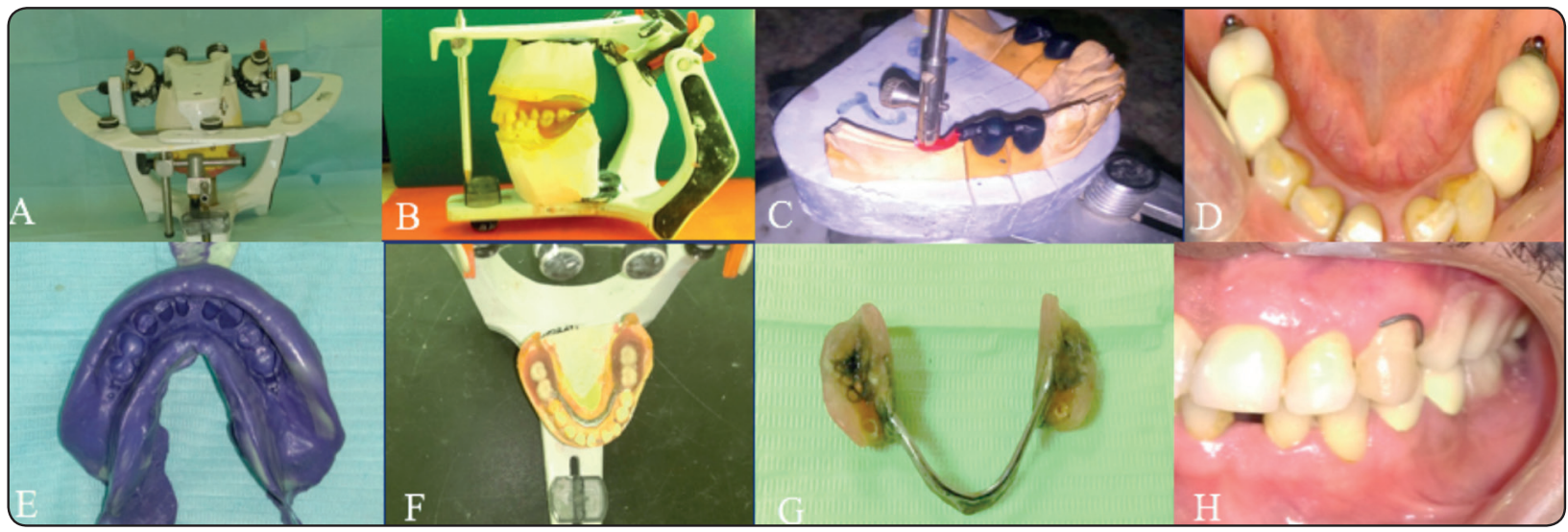

Fig. (2) (prosthetic procedure-attachment retained RPD) A) Facebow transfer (facial view) B) Diagnostic setup left side C) Mounting of attachments D) Insertion of Extra coronal attachment E) Final impression recording Extra coronal attachment F) RPD fabrication G) Attachment housing (pick up) H) Denture insertion (occlusion) 


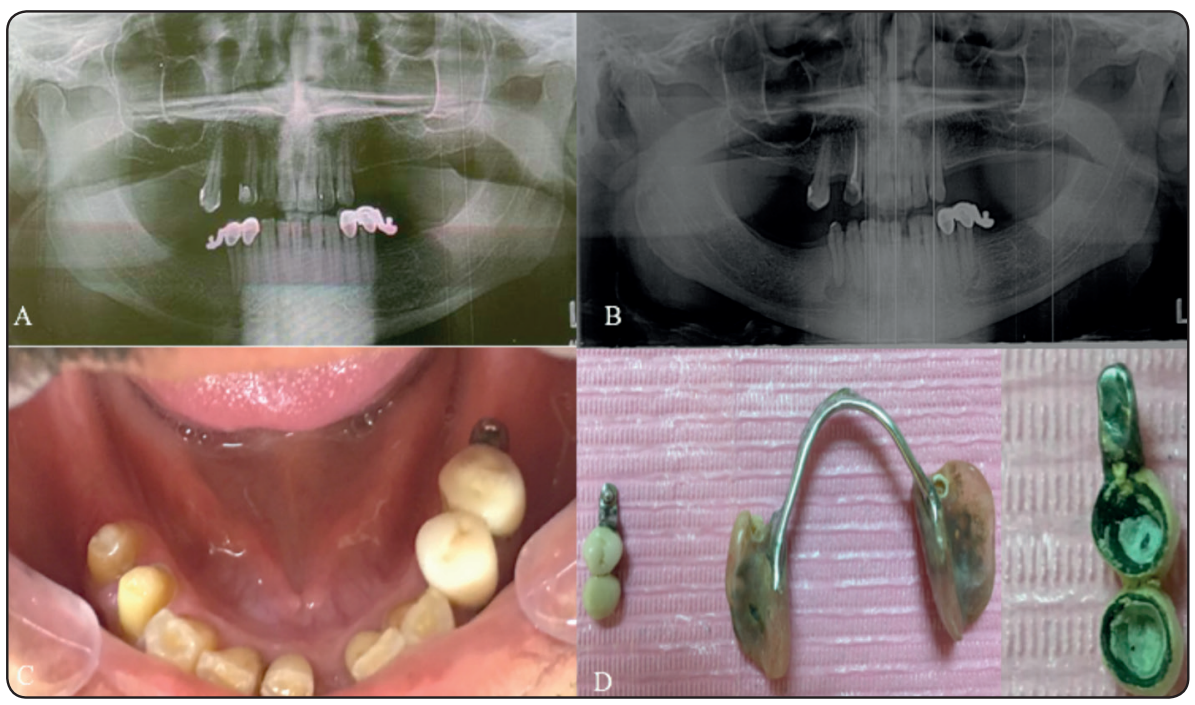

Fig. (4) follow up-attachment retained $R P D$.

A) Panoramic radiograph (baseline)

B) Panoramic radiograph (1 year) periapical lesions around right abutments

C) Inflamed gingiva of the right distal abutments

D) Loss of the right extracronal attachment housing and dettachment of the crowns from the abutments

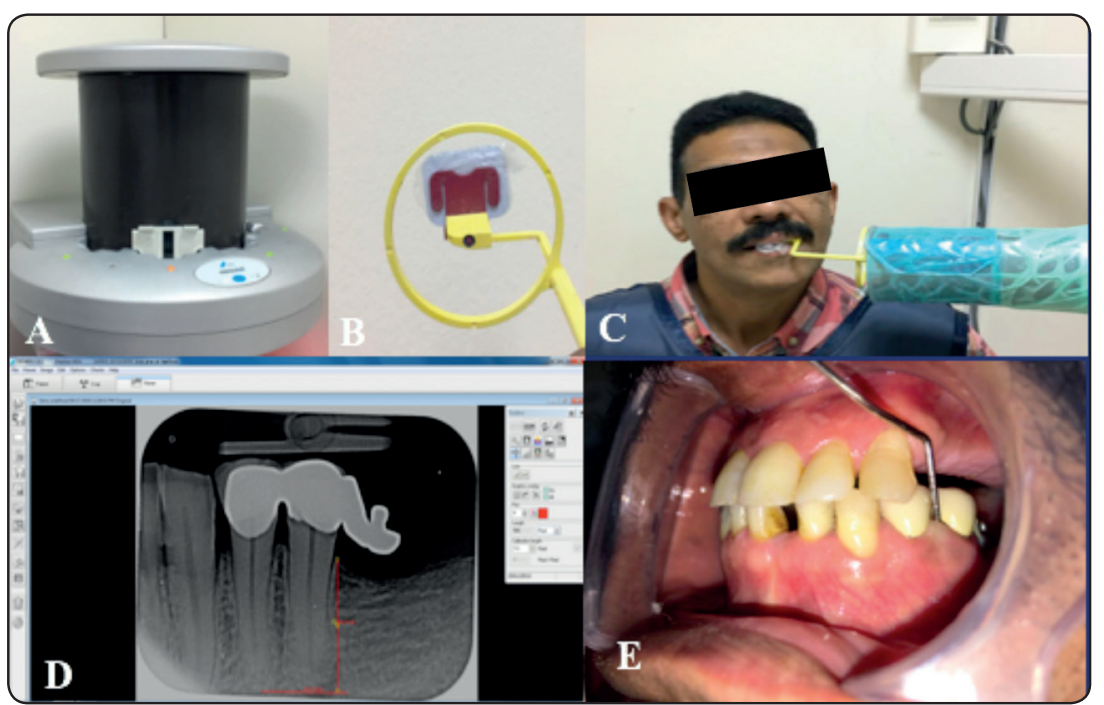

Fig. (5) (follow up-attachment retained RPD)

A) vista scanner

B) indicator arm and the aiming ring, Film PSP

C) (Orix $\mathrm{X}$ ray machine) Long cone paralleling technique

D) Bone height measurement (distal abutment)

F) Pocket depth measurement (distal abutment)

study groups at base line and 6 month after treatment as shown in table (1) and figure (5). Better results were recorded in the attachment group than in the clasp group (i.e., increased OES and decreased OHIP-14 as well as CFQ after-treatment percentage of change), the results of Mann-Whitney U test for independent samples presented a significant difference in OHIP-14 $(\mathrm{P}=0.002)$ and OES $(\mathrm{P}<0.001)$ while no significant difference in $\mathrm{CFQ}$ between both groups $(\mathrm{P}=0.191)$ was revealed.

Within group comparison of QOL scales between before and after treatment are presented in table (2)
Better results were recorded using the three questionnaires in the attachment retained RPD group and the clasp retained RPD group. Using Wilcoxon signed rank test, significant difference between before and after treatment scores in OHRQoL, OES and CFQ questionnaires in the clasp retained partial denture group with $\mathrm{P}$ value $=0.001,0.001$ and 0.003 respectively was found. Regarding the attachment retained RPD group, there was a significant difference between before and after treatment scores in OHRQoL, OES and CFQ questionnaires with $\mathrm{P}$ value $=0.001$ for the three questionnaires. 
TABLE (1) Percentage of change between the study groups at base line and 6 month after treatment.

\begin{tabular}{|l|l|l|l|l|}
\hline \multirow{4}{*}{ Group } & & OHRQoL-\%Change & OES-\%Change & CFQ-\%Change \\
\hline \multirow{5}{*}{ Clasp } & Mean & -40.79 & 20.06 & -33.73 \\
\cline { 2 - 5 } & $\mathrm{N}$ & 13 & 13 & 13 \\
\cline { 2 - 5 } & Std. Deviation & 14.323 & 7.991 & 18.633 \\
\hline \multirow{3}{*}{ Total } & Mean & -61.19 & 45.21 & -43.94 \\
\cline { 2 - 5 } & $\mathrm{N}$ & 13 & 13 & 13 \\
\cline { 2 - 5 } & Std. Deviation & 12.732 & 14.806 & 19.577 \\
\hline & Mean & -50.99 & 32.63 & -38.83 \\
\cline { 2 - 5 } & N & 26 & 26 & 26 \\
\cline { 2 - 5 } & Std. Deviation & 16.864 & 17.330 & 19.436 \\
\hline
\end{tabular}

\section{Survival rate}

The 24 months' survival rate of terminal abutments in clasp retained RPD group was $100 \%$ while for attachment retained RPD group was $84.6 \%$. A non-statistically significant difference between groups (P value=0.149) was found. fig 6,7

\section{Radiographic Evaluation}

For the two groups, mean change percentage was calculated.

Bone height (Base line)-Bone height (Post-operative) $\times 100$ Bone height (Base line)

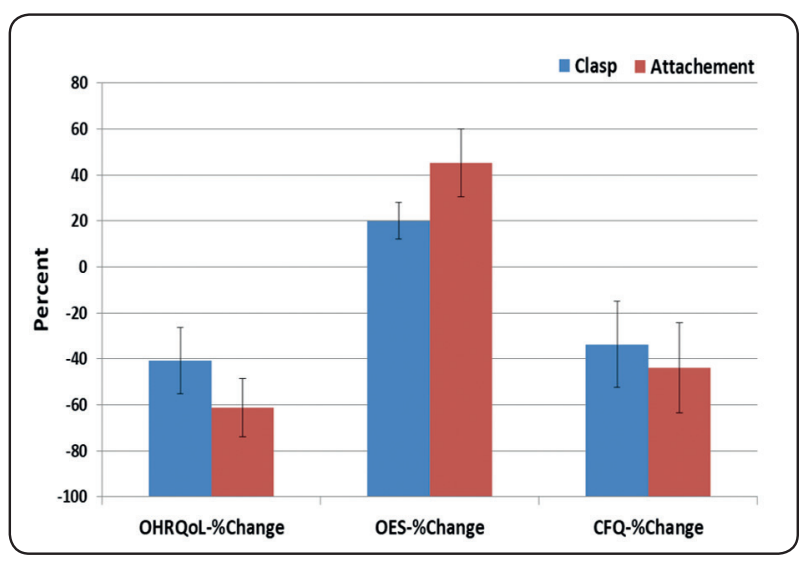

Fig. (5) The percentage of change between the study groups at base line and 6 month after treatment

TABLE (2) Within group comparison of QOL scales between before and after treatment

\begin{tabular}{|l|l|l|l|l|l|l|l|}
\hline & & $\begin{array}{l}\text { OHR Q o L- } \\
\text { Before }\end{array}$ & OES-Before & CFQ-Before & $\begin{array}{l}\text { OH RQ oL- } \\
\text { After }\end{array}$ & OES-After & CFQ-After \\
\hline \multirow{4}{*}{ Clasp } & Mean & 26.46 & 54.46 & 20.92 & 15.38 & 65.23 & 13.54 \\
\cline { 2 - 8 } & $\mathrm{N}$ & 13 & 13 & 13 & 13 & 13 & 13 \\
\cline { 2 - 8 } & Std. Deviation & 4.176 & 2.989 & 3.040 & 3.330 & 3.193 & 2.665 \\
\hline \multirow{3}{*}{ Attachment } & Mean & 21.85 & 48.92 & 20.00 & 8.46 & 70.62 & 10.77 \\
\cline { 2 - 8 } & $\mathrm{N}$ & 13 & 13 & 13 & 13 & 13 & 13 \\
\cline { 2 - 8 } & Std. Deviation & 3.105 & 3.546 & 3.055 & 2.757 & 3.754 & 2.619 \\
\hline \multirow{3}{*}{ Total } & Mean & 24.15 & 51.69 & 20.46 & 11.92 & 67.92 & 12.15 \\
\cline { 2 - 7 } & $\mathrm{N}$ & 26 & 26 & 26 & 26 & 26 & 26 \\
\cline { 2 - 7 } & Std. Deviation & 4.305 & 4.278 & 3.023 & 4.630 & 4.381 & 2.949 \\
\hline
\end{tabular}


For the two groups, Independent t-test was used to compare bone height, and insignificant difference was found (P-value $>0.05$ ), table (3), fig (8).

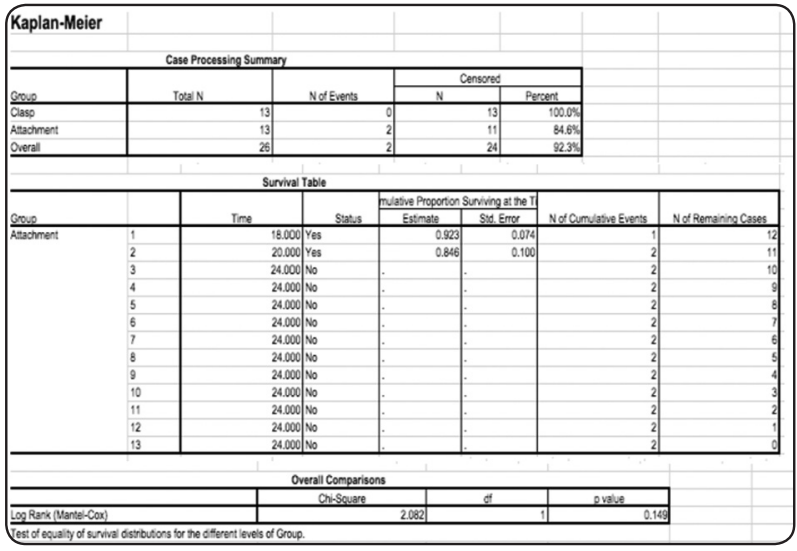

Fig. (6) Kaplan Meier analysis for survival rate of terminal abutments in both groups

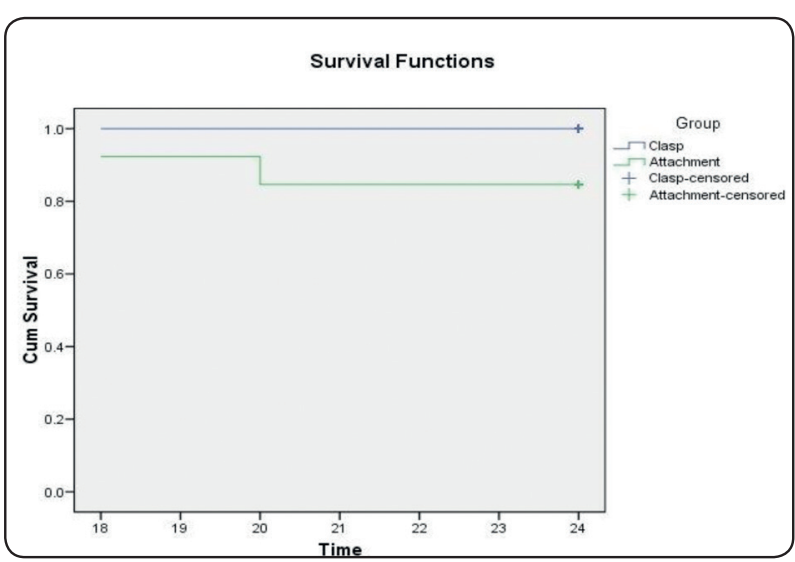

Fig. (7) Survival curve for clasp and attachment group

TABLE (3): Comparison Between Clasp and Attachment During Twenty-Four Months Follow Up Period:

\begin{tabular}{|c|c|c|c|c|c|}
\hline \multirow{2}{*}{ Bone Height } & \multicolumn{2}{|c|}{ Clasp } & \multicolumn{2}{c|}{ Attachment } & \multirow{2}{*}{ P-value } \\
\cline { 2 - 5 } & Mean & SD & Mean & SD & \\
\hline Baseline & 10.75 & 0.55 & 10.73 & 0.55 & $0.9469^{*}$ \\
\hline $\begin{array}{c}\text { Twelve } \\
\text { Months }\end{array}$ & 10.58 & 0.45 & 10.52 & 0.57 & $0.8306^{*}$ \\
\hline $\begin{array}{c}\text { Twenty-Four } \\
\text { Months }\end{array}$ & 10.42 & 0.42 & 10.33 & 0.72 & $0.78^{*}$ \\
\hline
\end{tabular}

M; Mean, SD; Standard deviation, P; Probability Level *insignificant difference

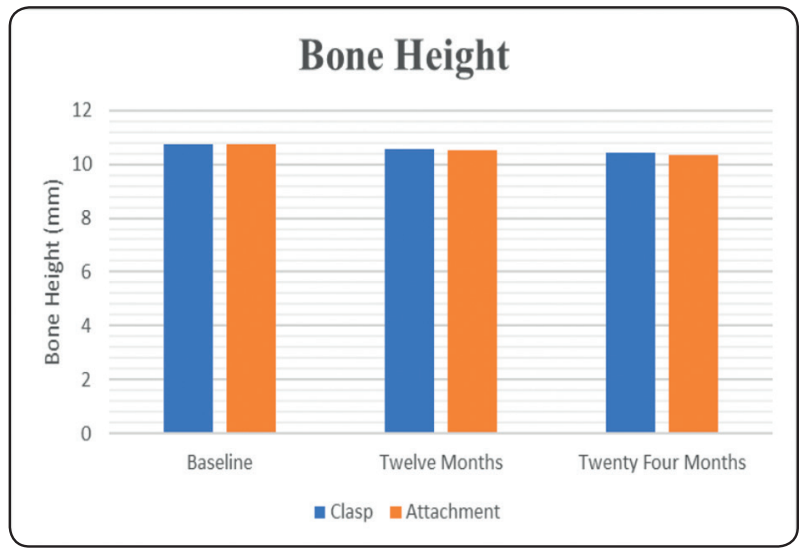

Fig. (8): Bone Height Comparison for Clasp and Attachment Groups

After mean change percentage calculation, significance between groups was calculated using $t$ test, and a significant difference was found between groups at baseline-twenty-four month's interval (P-value $<0.05)$, table (4), figure (9).

TABLE (4): Mean Change Percentage of Bone Height for Both Groups for Each Interval:

\begin{tabular}{cccccc}
\hline \multirow{2}{*}{$\begin{array}{c}\text { Bone Height } \\
\text { Change } \%\end{array}$} & \multicolumn{2}{c}{ Clasp } & \multicolumn{2}{c}{ Attachment } & P-value \\
\cline { 2 - 5 } & Mean & SD & Mean & SD & \\
\hline $\begin{array}{c}\text { Baseline-Twelve } \\
\text { Months }\end{array}$ & $1.58 \mathrm{a}$ & 0.49 & $1.96 \mathrm{a}$ & 0.60 & $0.2187 *$ \\
\hline $\begin{array}{c}\text { Twelve-Twenty } \\
\text { Four Months }\end{array}$ & $1.51 \mathrm{a}$ & 0.47 & $1.81 \mathrm{a}$ & 0.56 & $0.299^{*}$ \\
\hline $\begin{array}{c}\text { Baseline-Twenty } \\
\text { Four Months }\end{array}$ & $3.07 \mathrm{~b}$ & 0.094 & $3.73 \mathrm{~b}$ & 0.015 & $0.0001^{* *}$ \\
\hline P-value & $0.00^{* *}$ & $0.00 * *$ & \\
\hline
\end{tabular}

\section{*insignificant difference}

\section{**significant difference}

Values with same superscript letter in the same column were insignificant different

Values with different superscript letter in the same column were significant different

SD; Standard deviation, P; Probability Level 


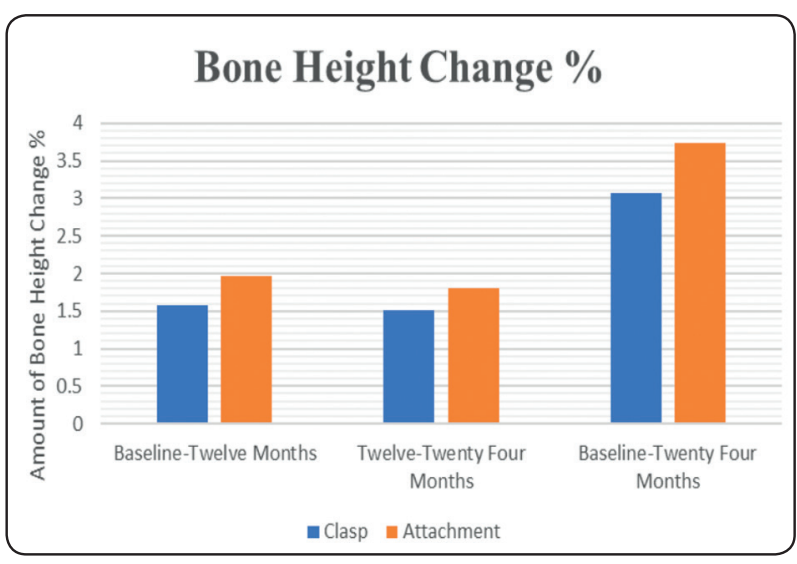

Fig. (9): Percentage of Bone Height Change for Clasp and Attachment Groups at Each Interval

One-way analysis of variance (AVONA) then Tukey`s post hoc test for multiple comparisons was used to evaluate effect of time on bone height change percentage for each group, it was revealed that there was overall significant difference for both groups between (Baseline-Twenty-Four Months) as (P-value $=0.0001)$, listed in table (4) and shown in figure (9). In addition, there was insignificant difference between Baseline-Twelve Months $(\mathrm{P}$-value $=0.2187)$ and between Twelve-TwentyFour Months intervals $(\mathrm{P}$ - value $=0.299)$ for both groups, listed in table (4) and shown in figure (9).

\section{Pocket depth}

A non-statistically significant difference was found between groups in percent change of mean probing pocket depth in the terminal abutments from base line to one year $(\mathrm{P}=0.4)$, baseline to 2 years $(\mathrm{P}=0.05)$ as well as from 1 year to 2 years $(\mathrm{P}=0.3)$. table 5, fig (10)
TABLE (5):

\begin{tabular}{|c|c|c|c|c|c|c|c|}
\hline \multirow{2}{*}{$\%$ change } & \multicolumn{3}{|c|}{ Attachment } & \multicolumn{3}{|c|}{ Clasp } & \multirow[b]{2}{*}{$\mathrm{p}$ value } \\
\hline & Mean & $\mathrm{SD}$ & $\mathrm{n}$ & Mean & SD & $\mathrm{n}$ & \\
\hline Baseline-1y & 5 & 15 & 13 & 4 & 15 & 13 & $0.433 *$ \\
\hline Baseline-2y & 17 & 21 & 13 & 5 & 16 & 13 & $0.057 *$ \\
\hline $1 y-2 y$ & 11 & 18 & 13 & 1 & 15 & 13 & $0.350 *$ \\
\hline
\end{tabular}

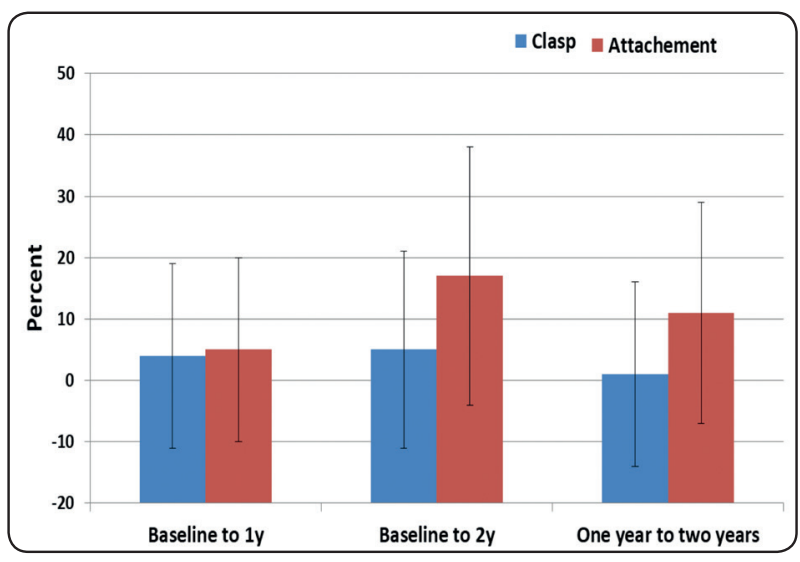

Fig. (10): Mean and SD of percent change between the different study time points between the 2 study groups

\section{DISCUSSION}

Although various treatment options are offered by implant therapy, still RPDs are the treatment of choice in partially edentulous patients with missing posterior teeth. ${ }^{29}$ Therefore, assessing outcomes with RPDs is very important and should not be ignored in relation to studies related to dental implants.

A properly designed RPD should prevent the destructive rotational movement around terminal abutments encountered in distal extension RPD which results from the difference in the displacements of the supporting tissues. ${ }^{30}$ 
It has been reported that at least two abutment teeth should be splinted when attachment RPD are used in order to make the stress patterns more favorable. ${ }^{31}$ In the present study, the first and the second premolars were splinted.

Resilient attachments have been reported to transmit more forces on the edentulous ridge and less forces on the abutments where the semi-precision produces the most favorable stress pattern ${ }^{32,33}$. A semi precision resilient extracoronal attachment was selected for this study to evade the abutments from unfavorable forces. ${ }^{34}$

Outcomes related to patients are extensively used in the evaluation of treatment results ${ }^{35}$ The OHIP is used for assessing the seven elements of OHRQoL. ${ }^{36}$ The OHIP-14 questionnaire is used in the assessment of the RPD in relation to physical, psychological and sociological factors. Chewing function is assessed using CFQ and Orofacial esthetics is evaluated using OES. It has been proposed that loss of denture retention of the dentures and impaired chewing ability can cause dissatisfaction. ${ }^{37}$ Other studies showed that improved aesthetic is more important than function. ${ }^{38} 39$

When compared to base line, better after treatment outcomes were observed in both the claspretained and the attachment-retained RPDs groups which can be attributed to successful outcome of RPD therapy in both groups. Nevertheless, better results were recorded in the attachment-retained RPD group when compared to the clasp-retained group with a significant difference in OHIP-14 $(\mathrm{P}=0.002)$ and $\mathrm{OES}(\mathrm{P}<0.001)$ while there was no statistically significant difference in CFQ between both groups ( $\mathrm{P}=0.191)$ This is in agreement with the results of a previous study ${ }^{40}$ which showed patient's satisfaction of (93.8\%) with RPDs retained with attachments compared to those retained with clasps (58.7\%). In addition, similar results were recorded in a study ${ }^{41}$ showing better results with attachment retained RPDs.
A non-statistically significant difference was reported in this study in the abutment survival rate between attachment retained RPD group and clasp retained RPD group ( $\mathrm{P}$ value $=0.149$ ), however two patients have lost one of their terminal abutments in attachment retained RPD group.

Also, a statistically non-significant difference was found in mean probing pocket depth of the terminal abutments in both groups, however the values of pocket depth were higher in patients with RPD retained with attachment. Therefore, the periodontal status of the attachment retained RPD may be the cause of the abutments failure reported in the attachment group. This finding is not in agreement with other studies which reported higher values of all periodontal parameter as BOP, PD, PI, CI, TM in patients with RPD's retained with claps compared with RPD's with attachment. ${ }^{42,43}$

Regarding bone height, a significant difference was reported in this study between both groups at baseline-twenty-four month's interval (P-value = 0.0001 ) in which more bone loss was found in the distal abutments of the attachment group which may also explain the abutments loss in this group.

Thus, despite of the non-statistically significant differences, a clinically significant difference was revealed, so further studies are required with larger sample sizes and longer follow up periods.

\section{CONCLUSION}

Within the limitations of the present study, all patients have shown improvement in OHRQoL, esthetics and chewing function after treatment with RPDs with better results in the attachment retained RPD. However, regarding the terminal abutment survival, mean probing pocket depth and bone height change, clinically significant better results were revealed in clasp-retained RPD compared to attachment-retained RPDs. 


\section{REFERENCES}

1. Dhingra, K.: Oral rehabilitation considerations for partially edentulous periodontal patients. J Prosthodont. 2012, 21, 494-513.

2. McKenna, G.; Allen, P.F.; O’Mahony D, et al: The impact of rehabilitation using removable partial dentures and functionally orientated treatment on oral health-related quality of life: a randomised controlled clinical trial. J Dent. 2015, 43, 66-71.

3. Tada, S.; Ikebe K.; Matsuda, K.; et al: Multifactorial risk assessment for survival of abutments of removable partial dentures based on practice-based longitudinal study. J Dent. 2013, 41, 1175-80.

4. Rehmann, P.; Orbach, K.; Ferger, P.; et al: Treatment outcomes with removable partial dentures: a retrospective analysis. Int J Prosthodont. 2013, 26, 147-50.

5. Behr, M.; Zeman, F.; Passauer, T.; et al: Clinical performance of cast clasp-retained removable partial dentures: a retrospective study. Int J Prosthodont. 2012, $25,138-44$.

6. Wostmann, B.; Budtz-Jørgensen, E.; Jepson, N.; et al: Indications for " removable partial dentures: a literature review. Int J Prosthodont. 2005, 18, 139-45.

7. Stegelmann, K.; Dirheimer, M.; Ludwig, E.; et al: Casecontrol study on the survival of abutment teeth of partially dentate patients. Clin Oral Investig 2012, 16, 1685-91.

8. Peter, E. Staubli,: Attachments \&Implants Reference Manual,6th Ed. Implant Dentistry. 1998, 7, 377.

9. Al-alsheikh, H.: A comparison of patient satisfaction and dentist evaluation of removable partial dentures therapy among saudi female patients. JPDA. 2011, 20, 239-44.

10. Knezović Zlatarić, D.; Celebić, A.; Valentić-Peruzović, M.; Jerolimov, V.; Pandurić, J.: A survey of treatment outcomes with removable partial dentures. J Oral Rehabil. 2003, 30, 847-54.

11. Reifel, N.; Rana, H.; Marcus, M.: Consumer satisfaction. Adv Dent Res. 1997, 11, 281-90. [http://dx.doi.org/10.117 7/08959374970110021101] [PMID: 9549994]

12. Yeung, A.; Lo, E.; Chow, T.; Clark, R.: Oral health status of patients 56 years after placement of cobalt-chromium removable partial dentures. J Oral Rehabil. 2000, 27, 1839. [http://dx.doi.org/10.1046/j.1365-2842.2000.00512.x] [PMID: 10784329]
13. Lalla, R.; Patton, L.; Dongari-Bagtzoglou, A.: Oral candidiasis: pathogenesis, clinical presentation, diagnosis and treatment strategies. J Calif Dent Assoc. 2013, 41, 263-8. [PMID: 23705242]

14. Petricevic, N.; Celebic, A.; Papic, M.; et al: The Croatian version of the Oral Health Impact Profile Questionnaire. Coll Antropol. 2009, 33, 841-47.

15. Slade, G,; Spencer, A.: Development and the evaluation of the Oral Health Impact Profile. Community Dent Health. 1994, 11, 3-11.

16. Larsson, P.; John, M.; Nilner K.; et al: Development of an Orofacial Esthetic Scale in prosthodontic patients. Int J Prosthodont. 2010, 23, 249-56.

17. Persic, S.; Milardovic, S.; Mehulic, K.; et al: Psychometric properties of the Croatian version of the Orofacial Esthetic Scale and suggestions for modification. Int J Prosthodont. 2011, 24, 523-33.

18. Persic, S.; Palac, A.; Bunjevac, T.; et al: Development of a new Chewing Function Questionnaire for assessment of a self-perceived chewing function. Community Dent Oral Epidemiol. 2013, 41, 565-73.

19. Bergman, B.: Periodontal reactions related to removable partial dentures: a literature review. Journal of Prosthetic Dentistry. 1987, 58, 454.

20. Drake, C.W. \& Beck, J.D. The oral status of elderly removable partial denture wearers. Journal of Oral Rehabilitation. 1993; 20, 53 .

21.Tuominen, R.; Ranta, K.; Paunio, I.: Wearing of removable partial dentures in relation to periodontal pockets. Journal of Oral Rehabilitation. 1989, 16, 119.

22. Chandler, J.; Brudvik, J.: Clinical evaluation of patients eight to nine years after placement of removable partial dentures. Journal of Prosthetic Dentistry. 1984, 51, 736.

23. Bergman, B.; Hugoson, A.; Olsson, C.: A 25 year longitudinal study of patients treated with removable partial dentures. J Oral Rehabil. 1995, 22, 595-9.

24. Behr, M.; Zeman, F.; Passauer, T.; Koller, M.; Hahnel, S.; Buergers, R.; et al: Clinical performance of cast claspretained removable partial dentures: a retrospective study. Int J Prosthodont. 2012, 25, 138-44.

25. Rehmann, P.; Orbach, K.; Ferger, P.; Wöstmann, B.: Treatment outcomes with removable partial dentures: a retrospective analysis. Int J Prosthodont. 2013, 26, 147-50. 
26. Slade GD, Spencer AJ. Development and evaluation of the Oral Health Impact Profile. Community Dent Health. 1994, 11, 3-11.

27. Larsson, P.; John M.; Nilner, K.; Bondemark, L.; List, T.: Development of an Orofacial Esthetic Scale in prosthodontic patients. Int J Prosthodont. 2010, 23, 249-56.

28. Persic, S.; Palac, A.; Bunjevac, T.; et al: Development of a new Chewing Function Questionnaire for assessment of a self-perceived chewing function. Community Dent Oral Epidemiol. 2013, 41, 565-73.

29. Tanasic, I.; Tihacek-Sojic, L.; Milic-Lemic, A.: Prevalence and clinical effects of certain therapy concepts among partially edentulous Serbian elderly. J Prosthodont. 2015. doi:10.1111/jopr.12261

30. Mcgivney, G.; Castleberry, D.(1995) McCracken's Removable Partial Prosthodontics, 9th edn, pp. 166, 331. C.V. Mosby Inc., New York.

31. El Charkawi H.; El Wakad T.: Effect of splinting on load distribution of extracoronal attachment with distal extension prosthesis in vitro. J Prosthet D. 1996, 76, 315-20.

32. Applegate OC. Essentials of Removable partial denture Prosthesis, ed1Philadelphia:Sauders, 1954.

33. Kratochvil, F.; Thompson, W.; Caputo, A.: Photoelastic analysis of stress patterns on teeth and bone with attachment retainers for removable partial dentures. Journal of Prosthetic Dentistry. 1981, 46, 21.

34. Igarashi, Y.; Ogata, A.; Kuroiwa, A.; Wang, H.: Stress distribution and abutment tooth mobility of distal-extension removable partial dentures with different retainers: an in vivo study. Journal of Oral Rehabilitation. 1999, 26, 111.
35. Locker, D.: Measuring oral health: a conceptual framework. Community Dent Health. 1988, 5, 3-18.

36. John, M.; Reissmann, D.; Feuerstahler, L.; et al: Exploratory factor analysis of the Oral Health Impact Profile. J Oral Rehabil. 2014, 41, 635-43

37 Bilhan, H.; Erdogan, O.; Ergin, S.; Celik, M.; Ates, G.; Geckili, O.: Complication rates and patient satisfaction with removable dentures. J Adv Prosthodont. 2012, 4, 109-15.

38 Graham, R.; Mihaylov, S.; Jepson, N.; Allen, P.: Bond S. Determining need for a removable partial denture: a qualitative study of factors that influence dentist provision and patient use. Br Dent J. 2006, 200, 155-8.

39 Koyama, S.; Sasaki, K.; Kawata, T.; Atsumi, T.; Watanabe, M.: Multivariate analysis of patient satisfaction factors affecting the usage of removable partial dentures. Int $\mathrm{J}$ Prosthodont. 2008, 21, 499-500.

40. Owall, B.: Precision attachment-retained removable partial dentures: Part 2. Long-term study of ball attachments. Int J Prosthodont. 1995, 8,21-8.

41. Shala, K.; Dula, L.; Pustina-Krasniqi, T.; Bicaj, T.; Ahmedi E.; Lila-Krasniqi Z.; Tmava-Dragusha A.: Patient's Satisfaction with Removable Partial Dentures: A Retrospective Case Series. The open dentistry journal. 2016, 10, 656 .

42. Wright PS, Hellyer PH. Gingival recession related to removable partial dentures in older patients. Prosthet Dent. 1995;74(6):602-7.

43. Linda J.; Dula Enis F.; Ahmedi Zana D.; Lila-Krasniqi Kujtim Sh Shala ; Clinical Evaluation of Removable Partial Dentures on the Periodontal Health of Abutment Teeth: A Retrospective Study . The Open Dentistry Journal, 2015, 9, 132-139. 